\title{
SUSTENTABILIDADE E EDUCAÇÃO: O REBAIXAMENTO DA EDUCAÇÃO À SUBMISSÃO DOS IMPERATIVOS DO CAPITAL
}

\section{SUSTAINABILITY AND EDUCATION: THE LOWERING OF EDUCATIONTO THE IMPERATIVES OF CAPITAL SUBMISSION}

\section{Luciano Accioly Lemos Moreira}

\section{RESUMO}

Analisamos neste artigo através do ponto de vista teórico marxiano o discurso da sustentabilidade defendido pela Organização das Nações Unidas (ONU), Banco Mundial e UNESCO a partir da década de 80 do séc. XX. O referido projeto propõe a transmissão de valores "éticos" aos indivíduos como a "saída" para a humanidade em crise. No entanto, o que se percebe por meio da análise do discurso da sustentabilidade é o rebaixamento da educação num duplo aspecto: em primeiro lugar, no esvaziamento da transmissão dos conteúdos científicos, estéticos e culturais decantados pela humanidade aos indivíduos em prol da transmissão de uma "ética" sustentável; num segundo aspecto, na transferência de conhecimentos "básicos"/mínimos para os indivíduos pobres/classe dominada sobreviver, manter sua existência e a ordem do capital. Esse tipo de educação, e consequentemente, esse tipo de homem da sustentabilidade, responde ideológica e politicamente às necessidades da manutenção da ordem e do respeito às premissas estruturais que sustentam a sociabilidade do capital e sua lógica produtiva desigual.

PALAVRAS-CHAVE: Sustentabilidade/educação/desigualdade/manutenção da ordem.

\section{ABSTRACT}

analyzed in this Article through the theoretical point of view marxiano the discourse of sustainability championed by the United Nations (UN), World Bank and UNESCO from the 1980s the 21st century. XX. The project, proposes the transmission of values "ethical" to individuals as the "exit" for humanity in crisis. However, which is incomprehensible by means of discourse analysis of 
sustainability is the debasing of education in a dual aspect: firstly, the emptying of the transmission of content scientific, aesthetic and cultural decantados by humanity to individuals in the interest of the transmission of a "ethics" sustainable; a second aspect, the transfer of knowledge"/"basic minimum for individuals poor/class dominated survive, maintain their existence and the order of the capital. This type of education, and consequently, this type of man of sustainability, responds ideological and politically to the needs of maintaining order and respect to the premise that structural support the sociability of capital and its logic productive patchy.

KEY-WORDS: sustainability/education/inequality/maintenance of order.

\section{INTRODUÇÃO}

Ao lançarem as bases para a construção de um mundo sustentável, a ONU e a UNESCO definem o corpo de ideias e ações que deverão nortear as políticas econômicas, sociais e ambientais, que preliminarmente servirá tanto às nações ricas como as pobres.

O conceito de sustentabilidade para a UNESCO (2005, p. 30) pode ser traduzido nos seguintes termos:

(Sd20) Sustentabilidade refere-se às maneiras de se pensar o mundo e as formas de prática pessoal e social que levam a:

> Indivíduos com valores éticos, autônomos e realizados;

$>$ Comunidades construídas em torno de compromissos coletivos, tolerância e igualdade;

$>\quad$ Sistemas sociais e instituições participativas, transparentes e justas, e

práticas ambientais que valorizem e sustentam a biodiversidade e os processos ecológicos de apoio à vida.

$\mathrm{Na}$ visão desse órgão internacional, deve-se pensar $e$ agir diferentemente, para que o processo de sustentabilidade do homem e do planeta se inicie. Se observarmos a sequência discursiva acima, perceberemos que a mudança se dá de maneira ascendente, ou seja, deve-se primeiramente 
transformar o indivíduo; em seguida, a comunidade; posteriormente, os sistemas e instituições sociais; e por último, o meio ambiente. O indivíduo dessa maneira converte-se no principal agente de mudança. Sem a sua inserção, os outros lugares sociais e o próprio meio ambiente não poderão ser alterados para a dinâmica da sustentabilidade. Por esse motivo, a educação torna-se, nesse momento, o principal lugar de propagação ideológica desse projeto de desenvolvimento. Para demonstrar tal questão, recorreremos ao documento da UNESCO (2005, p.43): (Sd21) A educação constitui o pilar central das estratégias para
promover e enraizar os valores e comportamentos que o
desenvolvimento sustentável exige. Como alguns pensadores
assinalaram: "necessita-se de uma educação transformadora: uma
educação que contribua a tornar realidade às mudanças
fundamentais exigidas pelos desafios da sustentabilidade. Para
acelerar o progresso em direção à sustentabilidade é necessário
tornar as relações entre os seres humanos e o mundo natural mais
calorosas e afetuosas, e buscar formas de desenvolvimento
ambientais e sociais mais responsáveis". A educação nos habilita
como indivíduos e como comunidades a compreendermos a nós
mesmos e aos outros e as nossas ligações com um meio ambiente
social e natural de modo mais amplo.

A educação nessa proposição configura-se no "pilar" para tal projeto. Dessa maneira, o termo exposto atribui como sentido para a atividade educativa o lugar de alicerce, a qual tem função central no enraizamento dos valores e comportamentos imprescindíveis para tal tarefa. De acordo com o discurso da sustentabilidade, a educação precisa promover/estimular/fomentar e enraizar/fixar valores e comportamentos entre os homens e dos homens com a natureza, fundada em sentimentos calorosos e afetuosos. A essência da educação nesse ínterim deixa de ser a transmissão de conhecimentos decantados pela humanidade aos indivíduos, para ser a transmissão de sentimentos calorosos e afetivos.

Continuando, conforme a UNESCO (2005, p.43), a educação detém um papel-chave ao "inspirar a crença que cada um de nós tem o poder e a responsabilidade de introduzir mudanças positivas em escala global'. Confirma-se a recorrência atribuída ao indivíduo quanto a sua capacidade e responsabilidade em operar as mudanças necessárias no mundo atual. Cada indivíduo, ao introduzir os valores da sustentabilidade, poderá transformar 
positivamente e globalmente a negatividade da relação entre os homens e o meio ambiente. E a educação, como já explicitado, carrega em sua essencialidade a missão de embutir "valores, comportamentos e estilos de vida necessários para um futuro sustentável' (UNESCO, 2005, p.44).

Podemos explicitar tal discurso da seguinte maneira:

\section{Projeto de Sustentabilidade}

Incorporação de valores sustentáveis + calorosos +

afetuosos

Eixo central da transmissão/fixação EDUCAÇÃo

$\longrightarrow$ Mudar indivíduo = transformação na

relação entre os homens e dos homens com a

natureza.

Segundo o projeto em análise, os valores se constituíram no conteúdo fundamental para a mudança social. Resta-nos saber quais são os "novos" valores sustentáveis que se oporão ao modo de ser da atualidade, como também, a função social que a educação terá nesse projeto político e ideológico da sustentabilidade em tempos de crise estrutural do capital.

\section{EDUCAÇÃO E SUSTENTABILIDADE: DA VIDA MISERÁVEL À MISÉRIA DA RAZÃO}

(Sd22) O elemento humano é agora amplamente reconhecido como a variante fundamental no desenvolvimento sustentável, tanto no que se refere ao desenvolvimento não-sustentável quanto em termos de esperança para um desenvolvimento sustentável. As relações humanas fundamentadas no próprio interesse (ganância, inveja e ambição pelo poder, por exemplo) mantêm uma distribuição de riqueza injusta, que gera conflito e leva a menosprezar a disponibilidade futura dos recursos naturais. Ao contrário, as relações caracterizadas pela justiça, paz e negociação de interesses mútuos geram mais igualdade, respeito e compreensão. São estas qualidades que irão fundamentar o desenvolvimento sustentável (DÉCADA DAS NAÇÕES UNIDAS DA EDUCAÇÃO PARA O DESENVOLVIMENTO SUSTENTÁVEL, 2005, p.42)

Observando a citação, constatamos a presença do dêitico temporal agora -, que possibilita, de modo implícito, a identificação de um diálogo entre duas formas de conceber o desenvolvimento. A primeira (implícita) - antiga, ultrapassada - que, na perspectiva do discurso da sustentabilidade, 
desvaloriza a humanidade, ou seja, desconsidera os valores humanos essenciais ao "novo" modelo desenvolvimentista. Contrapondo-se a essa concepção antiga, "agora" temos uma nova, denominada de sustentável, que considera o elemento humano "como a variante fundamental no desenvolvimento sustentável, tanto no que se refere ao desenvolvimento nãosustentável quanto em termos de esperança para um desenvolvimento sustentável".

Assim, por meio do movimento produzido pelo interdiscurso, o sujeito/enunciante apropria-se de elementos contidos na memória discursiva dos modelos desenvolvimentistas presentes na história do capitalismo - produz e mobiliza efeitos de sentidos de modo contraditório, negando e se opondo ao modelo de desenvolvimento fundado em valores da ganância, da inveja e do desejo pelo poder. Deve-se "agora”, de acordo com o discurso em análise, valorizar "as relações caracterizadas pela justiça, paz e negociação de interesses mútuos geram mais igualdade, respeito e compreensão. São essas qualidades que irão fundamentar o desenvolvimento sustentável" como possibilidade na construção de uma sociedade mais igualitária, respeitosa e compreensiva.

Segundo o discurso em análise, o modelo de desenvolvimento capitalista anterior ao desenvolvimento sustentável valorizava a produção de riqueza e de um consumo não-sustentável. Como efeito, as relações sociais se desenvolviam por meio de valores humanos interesseiros e egoístas. Contudo, sob a égide de um modelo fundado na sustentabilidade, "novos" valores entre os indivíduos poderão estar voltadas para a sustentabilidade do planeta.

Podemos perceber então que a problemática, de acordo com o ideal da sustentabilidade, centra-se na construção de um "outro" modelo de desenvolvimento fundado numa "outra" ética: a sustentabilidade. Assim, como efeito, a totalidade social capitalista que tem como base fundante o trabalho abstrato, produtor de riqueza por meio da exploração do homem pelo homem, mantém-se intocada. $O$ que se pode mudar, e se deve transformar por intermédio desse modelo de desenvolvimento, são os indivíduos, internamente, seu modo de ser, de fazer e de pensar. Pois mesmo assim, de acordo com o discurso da ONU, Banco Mundial e UNESCO, poderão construir uma sociedade "mais igualitária", mais respeitosa e mais compreensiva, porém, 
desistimos nesse projeto de uma humanidade igualitária, respeitosa e compreensiva. A modalização por meio do advérbio "mais" demonstra discursivamente a impossibilidade nesta sociedade antagônica regida pelo capital da igualdade efetiva entre os homens.

A educação, conforme os documentos em análise, para acelerar o

(Sd23) progresso em direção à sustentabilidade é necessário tornar as relações entre os seres humanos e o mundo natural mais calorosas e afetuosas, e buscar formas de desenvolvimento ambientais e sociais mais responsáveis (DÉCADA DAS NAÇÕES UNIDAS DA EDUCAÇÃO PARA O DESENVOLVIMENTO SUSTENTÁVEL, 2005, p.42).

As relações entre os homens e dos homens com a natureza, conforme o discurso acima, se encontra fria e sem afeto, por isso se propõe é torná-las calorosas e afetuosas. Sendo assim, vivemos num modelo relacional frio $e$ distanciado, e a ética da sustentabilidade poderá amenizar, ampliar e intensificar essa aproximação do homem consigo mesmo e com a natureza. Ao internalizar, por meio desse projeto social e cultural da sustentabilidade, valores que edifiquem relações mais humanas, produziremos riqueza, respeitando a natureza e o homem.

Importante percebermos que a educação defendida pelos órgãos internacionais se dá não apenas na e pela escola, mas em diversos lugares sociais.

(Sd24) A busca pelo desenvolvimento sustentável é multifacetada - não pode depender unicamente da educação. Muitos outros parâmetros sociais afetam o desenvolvimento sustentável, como, por exemplo, a governança, relações de gênero, formas de organização econômica e de participação dos cidadãos. Na realidade, seria preferível falar em aprendizagem para o desenvolvimento sustentável, já que aprender não está restrito à educação como tal. Aprender inclui o que acontece nos sistemas educacionais, mas se estende na vida cotidiana - de modo que importantes aspectos da aprendizagem acontecem em casa, em contextos sociais, em instituições comunitárias e no local de trabalho (DÉCADA DAS NAÇÕES UNIDAS DA EDUCAÇÃO PARA O DESENVOLVIMENTO SUSTENTÁVEL, 2005, p.42).

A formação para a ética da sustentabilidade, conforme os textos em análise, dá-se inicialmente na esfera individual, se estende para a família, afetando outros contextos sociais mais amplos e institucionais, e por fim, 0 local de trabalho. Interessante observar o trajeto de introjeção do ideal de sustentabilidade, pois ele exprime uma compreensão de como e do que é possível mudar na sociedade. 
Assim, de acordo com o discurso da sustentabilidade, ao mudar os indivíduos, muda-se o mundo, ou melhor, só é possível mudar a esfera pessoal, interna e individual de cada ser humano. Há no discurso da sustentabilidade uma inversão entre determinante e determinado, entre fundante e fundado, pois a totalidade social que tem como base fundante a produção se constitui no campo real de possibilidade da movimentação dos indivíduos e da efetivação e construção do seu ser. Exemplificando, transmitir valores do respeito à natureza, aos seres vivos e à sociedade por meio da educação aos indivíduos não rompe a dinâmica destrutiva operada na base produtiva do capital, que visa e estimula ações de exploração do homem e da natureza de modo ilimitado.

A política da sustentabilidade defendida pelas agências internacionais em análise propõe uma "renovação cultural" dos indivíduos. Na realidade,

(Sd25) o potencial da educação é enorme. Não apenas permite informar a pessoa, mas também pode mudá-la. Não só é um instrumento de ilustração pessoal, mas também um instrumento de renovação cultural (Educação para um futuro sustentável: uma visão transdisciplinar para ações compartilhadas/UNESC, 1999, p.73).

O plano do desenvolvimento sustentável tem como premissa o ideal de que a cultura destrutiva de épocas anteriores deve cessar, e isso só é possível renovando os aspectos culturais dos indivíduos. O papel fundamental dessa empreitada centra-se na educação. Contudo, percebemos que a educação para a sustentabilidade não é a mesma para os países ricos e pobres, pois tanto o sentido de qualidade quanto a finalidade social da educação diferem para essas duas realidades sociais.

(Sd26) Atualmente as pessoas estão, mais do que nunca, conscientes das realidades mundiais. Estamos começando a compreender os efeitos de nossas ações individuais e coletivas para nós mesmos e para a biosfera, em seu conjunto. O conceito de sustentabilidade é, em si, reflexo dessa nova consciência. Talvez estejamos avançando para a nova ética mundial que transcende todos os demais sistemas de lealdade e crenças, uma ética que tem suas raízes na consciência do caráter inter-relacionado e sagrado da vida. Terá essa ética comum o poder de motivar-nos para mudar o perigoso rumo atual? Sem dúvida, não há resposta simples para essa pergunta; o que podemos dizer é que sem um fundamento moral e ético, dificilmente a sustentabilidade se tornará realidade (Educação para um futuro sustentável: uma visão transdisciplinar para ações compartilhadas/UNESCO, 1999, p.72) 
O discurso da sustentabilidade proposto pela ONU/Banco Mundial e UNESCO se estrutura na crença de que é possível uma "nova ética", com valores que tornem a vida humana e sua relação com a natureza sustentáveis.

As relações entre os indivíduos em todos os setores sociais, políticos e culturais devem, por esse cabedal de ideias, ser modificadas e ressignificadas em prol da paz, da justiça, da negociação, da igualdade, do respeito e da compreensão. Outros valores e comportamentos, de acordo com a ONU, fundados nos direitos humanos e no respeito à natureza, influirão diretamente numa transformação de um modelo não-sustentável atual para um outro que garanta a existência presente e futura, sustentavelmente, da "humanidade".

Por esse intermédio, podemos inferir que o problema, de acordo com o projeto político em análise, encontra-se na ausência de uma consciência sustentável. E que por meio da educação poderemos reverter esse quadro destrutivo.

Todavia, sabemos que os valores da sustentabilidade propostos pelos projetos em questão têm seu fundamento e sentido na sociabilidade capitalista. Os valores, ou seja, o que útil e inútil, bom e ruim, sustentável e insustentável, são definidos pela forma de produção e reprodução da existência dos homens. Lukács (1981, p. 50) define a gênese ontológica de tal processo social:

Portanto, no que se refere à gênese ontológica do valor, devemos
partir do fato de que, no trabalho como produção de valores de uso
(bens), a alternativa do que é útil ou inútil para a satisfação das
necessidades entra como um elemento ativo do ser social. Por isso,
quando abordamos o problema da objetividade do valor, percebemos
imediatamente que nele está contida uma aprovação da posição
teleológica correta, ou, melhor dizendo: a correção da posição
teleológica - tendo como pressuposto sua atuação correta - significa
que o respectivo valor foi realizadoconcretamente.

Assim, ontologicamente, e sob a égide de uma atividade produtiva do homem sobre a natureza fundada nos valores de uso, o valor tem sua origem na possibilidade concreta de o resultado dessa prática ser útil ou não às necessidades históricas desse indivíduo e/ou grupo humano. Mais adiante, o mesmo autor complementa:

Neste sentido, o valor que aparece no trabalho enquanto processo que reproduz valor de uso, é sem nenhuma dúvida objetivo. Não só porque o produto pode ser medido a partir da posição teleológica, mas também porque esta mesma posição teleológica pode ter a sua existência objetiva e válida demonstrada e comprovada, na sua 
relação de « se... então», com a satisfação da necessidade (LUKÁCS, 1981, 50).

Lukács, no entanto, nos adverte que a existência dos indivíduos não se resume à produção de suas vidas pelo e no trabalho. Os valores surgem dessa base material, e, por meio de muitas outras mediações sociais, políticas, ideológicas e culturais de cada momento histórico, tornarão e darão o sentido histórico do que é útil ou não saber, praticar, ter e ser.

Contudo, no capitalismo, na base produtiva, o eixo norteador do sentido da vida, a satisfação das necessidades humanas é subordinada aos imperativos dos valores de troca, ou melhor, do lucro de uns sobre o trabalho de muitos.

Desse modo, será possível desenvolver uma educação no capitalismo voltada à sustentabilidade entre os seres humanos e o mundo natural?

Tonet (2005, p.129) atinge certeiramente tal problemática ao afirmar que:

\begin{abstract}
Consideremos: qual é o valor supremo que rege esta forma de sociabilidade? Parece-nos que não há dúvida de que a produção de mercadorias e, portanto, a reprodução do próprio capital. Qual é o valor supremo proclamado pela ética dominante? A vida humana, na sua forma mais digna possível. É evidente que entre esses dois valores há uma incompatibilidade radical. A produção de mercadorias implica, necessariamente, a transformação do próprio homem em mercadoria e, portanto, a manutenção da exploração do homem pelo homem. A conseqüência disto é a completa destituição do sentido mais genuíno da vida humana.
\end{abstract}

Com isso, percebemos que há uma fratura, e um distanciamento, entre o ser dos homens, e o dever ser. Constatamos, de maneira concreta, o ser dos homens se dirigir para a sua desumanização, numa produção que os transforma em mercadoria. Por outro lado, o dever ser dos valores desejados e propostos pela ONU, Banco Mundial e UNESCO se direciona, pelo menos como discurso, para a solidariedade, justiça e preservação da vida e da natureza. Essa fratura tem uma intenção e uma funcionalidade na continuidade do sistema capitalista. É por intermédio de um falseamento socialmente necessário que o discurso da sustentabilidade faz sentido. No capital, os valores éticos propostos pelos documentos em análise apenas existem como um desejo a ser constantemente, e parcialmente, conquistado. Tonet (2005, p.129) esclarece essa questão do seguinte modo: 
A um ser que se move no sentido cada vez mais individualista, opõese o dever de ser solidário. A uma realidade objetiva que está nucleada, cada vez mais, pelo interesse privado, se opõe o dever de preocupar-se com o interesse público, com o bem comum. A uma lógica que, por exigência da reprodução do capital, caminha sempre mais no sentido da degradação da natureza, opõe-se o dever de ter maior respeito pela natureza. E assim por diante. Estamos diante de uma clara visão idealista da problemática dos valores. O que leva a pensar, por exemplo, que se nos conscientizarmos de que temos de ser solidários, justos, e pacíficos, o mundo se tornará ipso facto solidário, justo e harmônico.

O discurso da sustentabilidade ancorado em valores da justiça, igualdade, respeito ao homem e à natureza cumpre uma função ideológica imprescindível na manutenção desse sistema social em crise. Tal discurso detém um caráter regulador das práticas e dos conflitos sociais, direcionandoos a horizontes que não ultrapassem a lógica do sistema do capital. O discurso da sustentabilidade, com sua qualidade de convencimento político, social e ideológico, pavimenta, mesmo que contraditoriamente, e nunca de maneira homogênea, os passos dos homens a caminhos estranhos a sua humanização. Nesse processo, afirma-se o mundo das coisas e das mercadorias, negando-se a força social e humana, a qual transforma e constrói seu mundo, por meio de sua atividade.

A totalidade social, que é um complexo de complexos, e processualmente construída, se apresenta como um campo de possibilidades nas quais as individualidades humanas podem, por sua atividade, satisfazer suas necessidades sociais e históricas. Não temos a menor dúvida de que há na atualidade, a necessidade imperiosa de valores éticos verdadeiramente universais e humanos, no entanto, devemos relacionar ontologicamente as esferas da necessidade e da possibilidade. Pois é impossível aliar a existência desses valores numa sociedade fundada na desigualdade e na exploração. É no campo da possibilidade econômica, social e historicamente determinada, que as necessidades podem efetivar-se, tornando-se reais. Com isso, no movimento da totalidade capitalista fundada em relações conflitantes/adversas/explorativas, é interditada, como possibilidade efetiva, a existência de valores substantivamente humanos e universalmente igualitários. Apenas numa outra forma e num outro modo de se produzir, nos quais as relações entre os homens e os países sejam desenvolvidas de maneira livre, 
associada e consciente, é que teremos em construção a formação de um outro ser culturalmente sustentável.

O segundo sentido/aspecto que podemos suscitar através da análise sobre o papel da educação para o projeto de sustentabilidade dá-se no possível rebaixamento da função essencial da educação no processo de humanização dos indivíduos. Conforme o projeto em análise:

(Sd27) A visão de um mundo mais equitativo é inerente ao conceito de desenvolvimento sustentável. Essa meta apenas pode ser alcançada proporcionando-se aos menos favorecidos e às suas famílias meios de progredirem. E, entre esses meios, o mais essencial é a educação, especialmente, a educação básica (Educação para um futuro sustentável: uma visão transdisciplinar para ações compartilhadas/UNESCO, 1999, p.47).

Através do enunciado acima, a formação educacional se diferencia segundo a classe social da qual os indivíduos façam parte. Desse modo, é definido pelo projeto de sustentabilidade que os "menos favorecidos" devem ter uma formação voltada para a educação básica. Inicialmente, entendemos que ser "menos favorecido" é situar-se num sistema social em que, por algum motivo, o indivíduo encontra-se desprotegido. A primeira indagação que suscita tal problemática é compreender do que o indivíduo necessita proteger-se, ou ser ajudado/auxiliado, para poder existir nessa sociedade. Há, de modo oculto nesse discurso, a naturalização da desigualdade social, econômica e cultural, pois se existem os "menos" favorecidos, do mesmo modo, há na realidade os "mais favorecidos". Dessa maneira, alguns, pela própria natureza, nasceram com a capacidade maior de proteger-se e de enriquecer-se que outros. Sendo assim, os mais favorecidos podem e devem tanto cuidar de suas vidas, como também proteger a vida dos menos favorecidos. Continuando, sobre este mesmo ponto, naturaliza-se nesse projeto de sustentabilidade um duplo aspecto: primeiramente, o lugar social das classes dominantes e dominadas, como também torna o sistema capitalista uma força estranha/fetichizada, em que sua existência e movimento são fruto de forças incapazes de ser radicalmente modificadas. Mészáros (2007, p.295) acrescenta:

A sociedade capitalista resguarda com vigor não apenas seu sistema de educação contínua, mas simultaneamente também de doutrinação permanente, mesmo quando a doutrinação que impregna tudo não parece ser o que é, por ser tratada pela ideologia vigente "consensualmente internalizada" como o sistema de crença positivo 
compartilhado de maneira legítima pela "sociedade livre" estabelecida e totalmente não-objetável. Ademais, o que torna as coisas ainda piores é que a educação contínua do sistema do capital tem como cerne a asserção de que a própria ordem social estabelecida não precisa de nenhuma mudança significativa. Precisa apenas de uma regulação mais exata em suas margens, que se deve alcançar pela metodologia idealizada do "pouco a pouco". Por conseguinte, o significado mais profundo da educação contínua da ordem estabelecida é a imposição arbitrária da crença na absoluta inalterabilidade de suas determinações estruturais fundamentais.

Outro aspecto a ser analisado na sequência discursiva 27 é que não é qualquer educação que deverá ser transmitida para os "menos favorecidos", mas uma educação "básica". A terminologia "básica" tem uma rede de memória bastante significativa para a nossa análise: quando queremos atribuir a realização de uma satisfação mínima para algum fator, dzemo-la "básica". Exemplificando: cesta básica, roupa básica, educação básica, educação fundamental... Desse modo, se a cesta básica é definida como os produtos mínimos necessários à sobrevivência de uma família pobre/menos favorecida, a roupa básica cumpre a função mínima de vestir-se para ocasiões discretas; a educação básicalfundamental exerce a função em relação ao conhecimento mínimo necessário para o pobre existir sustentavelmente.

Complementando:

(Sd28) É preciso considerar a necessidade de educar "tanto o coração quanto a razão" e que os assuntos em questão estão relacionados mais com a ética e a justiça social do que com as considerações baseadas no conhecimento científico. Para tanto, é importante nos direcionarmos para uma progressiva internalização de novos princípios dentro de nossa cultura educacional (Educação para um futuro sustentável: uma visão transdisciplinar para ações compartilhadas/UNESCO, 1999, p.95).

Há um jogo de sentidos neste parágrafo que define a "qualidade" e o objetivo da educação sustentável para os países/indivíduos pobres. Segundo o trecho acima, é necessário educar o coração e a razão, pois a ética e a justiça social devem ser à base dessa ação. Contudo, já que a sustentabilidade é o resultado de valores éticos mais igualitários, justos e respeitosos, entende-se que a educação do coração, ou melhor, dos sentimentos/valores/comportamentos é superior e essencial na aplicação da sustentabilidade. Diferentemente, a razão, fruto do conhecimento científico/estético/filosófico, detém um valor de menor grandeza neste projeto. Assim, educar o coração com as qualidades de respeito e amor pela natureza poderá reverter o processo não-sustentável, que apenas a ciência, a pura 
razão da cientificidade moderna, não conseguiu. Torna-se claro neste momento o diálogo do discurso da sustentabilidade com a ciência da modernidade, no qual a última pregava o progresso científico/industrial como produtor de riqueza que colocou a humanidade na possibilidade da extinção. Do contrário, educar/desenvolver o coração/sentimento poderá garantir a continuidade sustentável da vida humana e do planeta. Seguindo na análise:

(Sd29) A Conferência Mundial sobre a educação para todos usou a expressão "educação fundamental" para se referir a todas as formas de educação e de capacitação organizadas que satisfaçam as necessidades básicas das pessoas, incluídas as de alfabetização e aritmética básica, assim como as de conhecimento gerais, atitudes, valores e comportamentos que necessitam para sobreviver, desenvolver sua capacidade, viver e trabalhar dignamente, melhorar seu nível de vida a partir do ponto de vista qualitativo, adotar decisões fundamentadas e seguir aprendendo (Educação para um futuro sustentável: uma visão transdisciplinar para ações compartilhadas/UNESCO, 1999, p.47).

Educação "fundamental" é o limite permitido e defendido por tal projeto em relação aos pobres. Educação “fundamental” restringe o ensino ao processo de alfabetização, de domínio da aritmética básica e absorção de conhecimento/valores/comportamentos imprescindíveis para a sobrevivência dos indivíduos pobres. O ensino para a sustentabilidade deve desenvolver capacidades nos pobres para continuarem pobres, sem que interfiram e ameacem a ordem vigente. O conhecimento mínimo, básico e fundamental, instrumentalizado e medido pelo coração, e não pela razão, rebaixa a função da educação à internalização de um agir, de um pensar, de um ser e de um conviver voltado à manutenção do status quo. Devo, segundo o discurso da sustentabilidade, conhecer apenas e tão somente o necessário para sustentarme neste mundo. De maneira pragmática, a utilidade do conhecimento é limitada à resolução das questões mais imediatas na manutenção da existência; sobreviver é o limite do conhecimento.

A educação para a sustentabilidade é a

(Sd30) chave para estabelecer e reforçar o regime democrático, para um desenvolvimento, ao mesmo tempo, sustentável, humano, e para uma paz fundada no respeito mútuo e na justiça social. De fato, em um mundo em que a criatividade e o saber cumprem um papel cada vez mais importante, o direito à educação não é nada mais do que o direito de participar da vida do mundo moderno (Educação para um futuro sustentável: uma visão transdisciplinar para ações compartilhadas/UNESCO, 1999, p.48). 
Na sequência supracitada, é estabelecido que a educação para os pobres deve garantir e promover a democracia, a sustentabilidade e a paz. Com isso, o projeto de sustentabilidade produz um efeito ideológico de circularidade/manutenção da pobreza a níveis seguros em relação à classe dominante. Por fim, é a criatividade, ou melhor, a capacidade individual de criar e perceber as oportunidades presentes no seu cotidiano que fará com que cada um participe, ou não, do mundo moderno. $O$ ideal de sustentabilidade neste momento aproxima-se do ideal da empregabilidade, pois a empregabilidade como também a sustentabilidade, deslocará os problemas sociais para o campo da individualidade burguesa, em que cada um, por si só, deve sustentar-se, ou melhor, autossustentar-se.

O projeto de sustentabilidade implantado pelos órgãos internacionais em análise propõe a necessidade de uma modificação na forma das relações entre os homens e o meio ambiente. Para esse propósito, a educação escolar deve priorizar a inculcação de valores nos indivíduos que propiciem essa transformação. Vejamos o recorte extraído do documento:

(Sd31) O elemento humano é agora amplamente reconhecido como a variante fundamental no desenvolvimento sustentável, tanto no que se refere ao desenvolvimento não-sustentável, quanto em termos de esperança para um desenvolvimento sustentável. As relações humanas fundamentadas no próprio interesse (ganância, inveja e ambição pelo poder, por exemplo) mantêm uma distribuição de riqueza injusta, que gera conflito e leva a menosprezar a disponibilidade futura dos recursos naturais. Ao contrário, as relações caracterizadas pela justiça, paz e negociação de interesses mútuos geram mais igualdade, respeito e compreensão (DÉCADA DAS NAÇÕES UNIDAS DA EDUCAÇÃO PARA O DESENVOLVIMENTO SUSTENTÁVEL, 2005, p.42).

Na defesa de uma "nova" relação sociocultural para a sustentabilidade, a educação se configura num instrumento essencial para a formação desse "novo" ser. O fim do processo educativo na atualidade centra-se na transmissão de valores da justiça, da paz e da negociação, com o objetivo, segundo a ONU, de inverter um progresso que, anterior ao projeto de sustentabilidade, priorizava interesses individualistas, e como efeito disso, teríamos a má distribuição da riqueza. Com isso, podemos refletir inicialmente que a produção de riqueza sob a regência do capitalismo não se configura no problema da insustentabilidade atual, mas na produção de riqueza sob a regência de valores egoístas. A insustentabilidade é fruto da ganância, do 
poder, da inveja e ambição entre os homens, e desses com a natureza; o que provoca a não-sustentabilidade são os valores deturpados e desmedidos dos indivíduos que intentam acumular sem preocupar-se com o futuro das gerações e do planeta. Seguindo essa lógica argumentativa, a educação se transforma no eixo central da mudança, pois com a práxis educativa é possível reverter esse processo. A educação, portanto, deverá desenvolver nos indivíduos:

(Sd32) Respeito pela dignidade e pelos direitos humanos de todos os povos em todo o mundo e compromisso com a justiça social e econômica para todos;

Respeito pelos direitos humanos das gerações futuras e o compromisso em relação à responsabilidade intergeracional;

Respeito e cuidado pela grande comunidade da vida em toda a sua diversidade, que inclui proteção e restauração dos ecossistemas da Terra;

Respeito pela diversidade cultural e o compromisso de criar local e globalmente uma cultura de tolerância, de não violência e de paz (DÉCADA DAS NAÇÕES UNIDAS DA EDUCAÇÃO PARA O DESENVOLVIMENTO SUSTENTÁVEL, 2005 p.43).

Há, no enunciado acima citado, um sentido recorrente que é o de respeito. Deve-se, segundo o discurso da ONU, por intermédio da educação, formar indivíduos que respeitem a dignidade, os direitos humanos, os povos, a justiça social e econômica, as futuras gerações, a comunidade da vida, a diversidade e o ecossistema. Se realizarmos um gesto de leitura sobre este movimento de sentidos, poderemos primeiramente afirmar que a ausência de respeito, a falta da obediência em relação às normas sociais e humanas leva a um desacato dos indivíduos em relação aos direitos dos demais seres humanos e ao meio ambiente. A internalização do respeito por meio de valores sustentáveis produzirá uma cultura de paz, não violência e tolerância. Continuando a análise, observaremos que o respeito terá como efeito a construção da paz, da tolerância e da não violência. Os sentidos das palavras citadas nos provocam um questionamento. O que poderá ameaçar a tranquilidade, a ordem das coisas e provocar violência? Quem ou o que deve tornar-se inofensivo? A quem interessa a formação de indivíduos passivos? Essa e outras questões nos incomodam em face dos sentidos remexidos por esses enunciados. O que fica claro é que os limites da lei, da ordem, da propriedade privada, dos direitos e deveres da cidadania e a democracia não podem ser desrespeitados pelos pobres, e tampouco ultrapassados dado que 
sem esse cumprimento, a "vida" e o "planeta", segundo os órgãos internacionais, estarão em "perigo". De acordo com Orlandi (2008, p.127):

Através das estruturas que lhe são próprias, toda língua está necessariamente em relação com o não-lá, com o não-mais-lá, com o jamais lá da percepção imediata. Na língua "se inscreve assim a eficácia omni-histórica da ideologia como incontornável tendência em representar as origens e os fins últimos, o que está além, o para lá e o invisível" (M. Pêcheux, 1980, p.54).

Indo além do sentido imediato, rastreando o espaço de significação do silêncio, percebemos os sentidos que se quer/precisa silenciar no discurso da sustentabilidade. Vivemos numa época em que a insustentabilidade não se resume à destruição do meioambiente, mas também, e principalmente, da vida humana. O desemprego ${ }^{1}$, a pobreza, o processo de favelização mundializada, as drogas, a fome ${ }^{2}$, o crime e demais problemas sociais se amplificam por todos os lugares do mundo.

Necessário explicar que o crime maior e fundamental, presente e constitutivo do sistema do capital, é silenciado pela própria necessidade reprodutiva do sistema. Explicando, a propriedade privada é fruto do roubo da expropriação do sobre trabalho do trabalhador explorado. O processo de constituição do trabalhador "livre e assalariado" do capitalismo ocorreu na sua forma de acumulação primitiva de modo violento, como o fruto da usurpação das terras dos servos e dos camponeses pelos grandes proprietários.

Pinassi (2009) explica que a partir da década de 70 do século passado, com a crise estrutural do capital, a criminalidade generaliza-se, adotando a racionalidade do capital, mais adequada à ampliação das oportunidades que

\footnotetext{
${ }^{1}$ Genebra, 28 jan (EFE).- A crise econômica mundial poderia deixar mais de 50 milhões de pessoas desempregadas em 2009, o que levaria a um total de 230 milhões, alertou hoje a Organização Internacional do Trabalho (OIT). Este é o pior cenário que prevê a OIT em seu relatório "Tendências Mundiais do Emprego", apresentado hoje em Genebra, no qual indica que o índice de desemprego no mundo poderia ficar em $7,1 \%$, o que provocaria um aumento de 50 milhões de desempregados. (http://noticias.uol.com.br- acesso em: 23 de novembro de 2009).

2 Segundo estimativas das Nações Unidas e de organizações de ajuda humanitária, o mundo está diante da ameaça de o século 21 tornar-se o século da fome. Principalmente os efeitos da crise econômica mundial teriam contribuído para o agravamento do problema, adverte o relatório de 2009 sobre a fome no mundo, divulgado nesta quarta-feira (14/10) em Roma pela Organização das Nações Unidas para Agricultura e Alimentação (FAO). Segundo o relatório, a quantidade de famintos em todo o planeta aumentou para 1,02 bilhão de pessoas. Este é o maior número desde 1970, informou a FAO. Em termos estatísticos, uma em cada seis pessoas no planeta não dispõe de alimentação suficiente. Em relação ao ano passado, aumentou em 100 milhões o número de pessoas que não têm o suficiente para comer. A maioria dos subnutridos e famintos vivem em países em desenvolvimento, explicou o relatório (http://www.dw-world.de/dw/article - acesso em 23 de novembro de 2009).
} 
Ihe foram abertas pela dinâmica imperialista. Outro ponto importante a ser esclarecido por nós, a partir da mesma autora e obra, é que há uma pequena parcela da criminalidade que dirige e domina suas operações criminosas de forma mundializada, contudo, estes são invisíveis aos olhos da Justiça; no entanto, uma maioria vive na bandidagem, reproduzindo sua existência: são pobres, analfabetos, subnutridos, aplacam a fome com cola ou crack, apanham, empunham armas desde cedo, e o único meio de afirmação da sua existência e da sua reduzida auto-estima é a violência e a bandidagem. A violência é a mediação mais familiar que os liga à vida, e no seu mundo não há lugar para a fantasia, para o glamour, nem para o romance; toda perspectiva é imediata, sem rodeios, inclusive a necessidade de recorrer ao crime.

As tensões sociais provocadas pelo processo destrutivo e desigual da produção e reprodução desumana do capital encontram-se, neste momento de crise estrutural e do desemprego crônico, num grau elevadíssimo, e as antigas saídas utilizadas pelo capital no intuito de deslocar os conflitos sociais tornamse, neste momento, impossíveis de ser operadas ${ }^{3}$. O sistema econômico do capital, dada a sua própria lógica lucrativa, funciona produzindo riqueza por meio da exploração. Dessa maneira, riqueza e pobreza caminham de modo necessário e natural nas relações produtivas deste sistema. Acúmulo e enriquecimento são produzidos ao preço da desumanidade e da pobreza de muitos, essa é a lógica. No momento em que o sistema opera em crise, e mesmo numa melhora econômica cada vez mais curta temporalmente, o sistema capitalista não consegue, devido a sua própria lógica, resolver os conflitos sociais produzidos no seu caminho reprodutivo. Ao contrário disso, as desigualdades sociais e econômicas se acumulam e se concentram em todo o mundo, necessitando para sua reprodução social de um controle ideológico cada vez mais refinado. O projeto da sustentabilidade é, no limite, a essencialidade de sua razão de ser e de existir, uma nova força ideológica e política redefinidora e adequadora dos trabalhadores empregados, desempregados e marginalizados à lógica reprodutiva de um sistema em decadência.

\footnotetext{
${ }^{3}$ No segundo capítulo, no qual abordamos a crise estrutural do capital, exemplificamos as antigas saídas utilizadas pelo sistema nas crises cíclicas e demonstramos a impossibilidade de o mesmo sistema utilizarse dos mesmos recursos a fim de deslocar os refreios a sua dinâmica expansiva e acumulativa do processo econômico capitalista.
} 
A contínua repetição do enunciado respeito em busca da tolerância, paz e não violência é direcionada aos que ameaçam a ordem, a aplicabilidade do projeto de sustentabilidade, a permanência e continuidade da subordinação dos países/indivíduos pobres em relação aos países/indivíduos ricos, da dominação da classe dominante em relação à dominada. Pois,

\begin{abstract}
incapaz de controlar as contradições cada vez mais agudas do seu sistema de funcionamento sociometabólico, o capital atinge, enfim, os limites dos seus defeitos mais estruturais, fato que dá origem a uma crise de proporções jamais vistas antes e, o que é mais grave, insolventes no interior dessa (des)ordem social.

Prova disso é que diante da impotência das políticas que até então garantiam a reprodução ampliada do capital, bem como a imperativa necessidade de manter a sua marcha incansável, o cenário vem apontando, pelo menos desde a década de 1970, para mudanças que parecem ativar o seu expansivo potencial de destruição (e só destruição), uma desmistificação da noção shumpeteriana de que o capitalismo é um sistema que funciona mediante a destruição produtiva. Os efeitos mais nefastos das medidas tomadas serão sentidos principalmente pelos trabalhadores, progressivamente golpeados em seus mais elementares direitos conquistados através de duros enfrentamentos sindicais e políticos. A degradação se completa com o desemprego estrutural e a precarização sem limites do trabalho, condições necessárias ao novo padrão de acumulação exigido (PINASSI, 2009, p.91).
\end{abstract}

Diante de tal situação econômica e social, a educação se configura num importante instrumento de amenização e cooptação dos indivíduos para a reprodução desse sistema em crise. $O$ processo educativo tem como essencialidade o poder e função de tornar os indivíduos aptos a reagir de modo adequado a cada situação social e histórica de sua época. A educação forma o tipo de homem necessário a cada momento histórico, o que se deve aprender, e não ser definido pelo indivíduo, ou seja, a autoconstrução de cada indivíduo numa sociedade de classe é determinada de modo mediato, contraditório, e em conflito, pela forma das relações econômicas e sociais que estruturam a totalidade social. Tonet (2005, p.215) elucida tal movimento:

A autoconstrução do indivíduo como membro do gênero humano é um processo subordinado à reprodução mais ampla da totalidade social. Vale dizer, o processo de autoconstrução do indivíduo como indivíduo humano, bem como as suas reações diante de novos problemas e acontecimentos, novas e imprevisíveis situações, não terá como pólo norteador o próprio indivíduo nem aqueles que atuam diretamente na dimensão educativa, mas a concreta totalidade social, cuja matriz é a economia. 
Necessário esclarecer que a determinação ontológica da economia não se dá de modo mecânico e absoluto; há nas outras esferas sociais, e no caso específico da educação, uma autonomia relativa quanto à esfera da economia, e a liberdade de escolha diante das alternativas abertas pela objetividade possibilita ao educador atuar de modo a contribuir na conservação ou no impulso para a mudança social ${ }^{4}$.

O modelo de educação atual corresponde ao tipo de homem hegemonicamente necessário ao sistema do capital em crise. A necessidade de um indivíduo que torne sustentável sua vida diante das tensões sociais e econômicas de nossa época, sem que essas tensões se tornem uma ameaça ao sistema, converte-se numa das finalidades essenciais da educação para a sustentabilidade. Desse modo, a formação do indivíduo deve ser centrada na introspecção de valores sustentáveis do respeito, em vez da transmissão de conteúdos científicos.

(Sd33) É preciso considerar a necessidade de educar "tanto o coração quanto a razão" e que os assuntos em questão estão relacionados mais com a ética e a justiça social do que com as considerações baseadas no conhecimento científico. Para tanto, é importante nos direcionarmos para uma progressiva internalização de novos princípios dentro de nossa cultura educacional (Educação para um futuro sustentável: uma visão transdisciplinar para ações compartilhadas/UNESCO - Brasília: Ed.IBAMA, 1999, p.95).

O "coração", que no caso em análise significa os valores da justiça e do respeito, se apresenta como o objetivo maior da atividade educativa da sustentabilidade; a aquisição dos saberes científicos pelo contrário, não é prioridade nessa formação. De acordo com o projeto da ONU, a ciência, o conhecimento, trouxe o progresso destrutivo e poluidor, e a aquisição de valores dos bons sentimentos e comportamentos trará a construção de um mundo "mais humano". A natureza essencial da atividade educativa se resume, conforme Tonet (2005, p.222), nos seguintes termos:

Propiciar ao indivíduo a apropriação de conhecimentos, habilidades, valores, comportamentos, etc., que se constituem em patrimônio acumulado e decantado ao longo da História da humanidade. Nesse

\footnotetext{
${ }^{4}$ Lembrando Tonet (2005), em uma sociedade de classes o interesse das classes dominantes será sempre o polo norteador da estruturação da educação de modo sistemático e hegemônico. A proposta de uma educação radicalmente contrária à ordem do capital, ou seja, emancipadora, só poderá ser explicitada em seus elementos gerais, sendo apenas efetivamente uma realidade educativa sistematizada e hegemônica num outro modo de produção.
} 
sentido, contribui para que o indivíduo se construa como membro do gênero humano e se torne apto a reagir diante do novo de um modo que seja favorável à reprodução do ser social na forma em que ele se apresenta num determinado momento histórico.

A atividade educativa se constitui, desse modo, numa mediação entre a produção do conhecimento acumulado historicamente pelo gênero humano e a individualidade carente dessa universalidade. Contudo, o processo de transmissão desse cabedal cultural do gênero humano universalmente produzido é repassado/transferido por meio de uma relação social e histórica, ou seja, o modo como se relacionam os indivíduos com a totalidade social permitirá o maior ou menor enriquecimento cultural desse ser social. Dessa maneira, as determinações econômicas, políticas e ideológicas de uma sociedade de classe refletirão na seleção dos conteúdos que devem ser aprendidos, nos valores que precisam ser assimilados, e no objetivo da atividade educativa ${ }^{5}$. A qualidade das relações sociais suscitadas na produção de suas vidas pelo trabalho refletirá na reprodução de um tipo de sociedade e de homem. O ser social é constituído ativamente, portanto, o modo como os homens produzem e reproduzem sua existência refletirá no modo e na formação escolar de cada momento histórico. Na sociedade desigual do capital, as relações entre os indivíduos e o gênero humano são perpassadas pelos interesses antagônicos de classe, e o acesso aos bens espirituais e materiais sofre um rebaixamento por meio dessa relação alienante.

Há na atualidade, no projeto de sustentabilidade, um duplo rebaixamento da função educativa. Primeiro, o conhecimento é subsumido à transmissão de valores da justiça, do respeito e da paz, relegando a transmissão da cultura decantada pela humanidade aos indivíduos pobres. Ou seja, deve-se formar um indivíduo passivo, que respeite a realidade caótica ao seu redor, adaptando-se e criando saídas para a sua sobrevivência cotidiana, sem que se coloque em risco a ordem estabelecida do capital. O segundo ponto reforça a desqualificação e o rebaixamento do nível de educação defendido por este projeto, pois o que se deve aprender são conhecimentos básicos, focalizados apenas e tão somente na sobrevivência dos indivíduos

\footnotetext{
${ }^{5}$ Importante frisar que essa hegemonia da educação dominante não será realizada sem conflito, sem falhas, nem possibilidades de sua superação radical por meio de outra ordem social.
} 
como pobres. Assim, nesse processo educativo, o pobre aprende/reforça e reproduz sua pobreza material e espiritual, e o mais importante, conserva a relação de produção que produz a pobreza e a exploração.

Sobre o primeiro aspecto da educação como transmissão de valores do respeito, Mészáros (2007, p.300) assevera que:

\begin{abstract}
A agenda do respeito consiste na ilusória projeção de resolver a crise de valores cada vez mais aprofundada - manifesta na forma de crescente criminalidade e delinqüência, ao lado da alienação cada vez pior do jovem em relação à sua sociedade - por um apelo direto e retórico à consciência dos indivíduos, postulando, em vão, o adequado "respeito" pelos valores da cidadania democrática. E quando toda essa pregação vazia fracassa, como tem de fracassar, uma vez que evita, como uma praga, as causas sociais dos sintomas negativos denunciados, as personificações políticas do alto escalão do capital, inclusive o mais alto deles, começam a falar de como podem identificar a futura criminalidade delinqüência já no "útero da mãe", indicando as medidas legislativas estatais autoritárias necessárias para lidar com a futura criminalidade potencial no estágio mais inicial possível. Essa linha de abordagem não é mais racional ou menos autoritária do que a defesa do Estado capitalista de adotar implacavelmente a luta ideológica com o intuito de vencer a já mencionada "guerra contra o terror". Ao mesmo tempo, o que se exclui absolutamente é a possibilidade de mudar as determinações estruturais da ordem social estabelecida que produzem e reproduzem os efeitos e consequências destrutivos. Cumpre negar de maneira categórica que possa haver alguma coisa seriamente errada com a sociedade tal como existe. Apenas os indivíduos tendenciosamente selecionados para serem repreendidos podem precisar de uma ação reparadora. E espera-se que essa ação corretiva seja proporcionada por um grupo privilegiado de indivíduos autodesignados - as personificações e os guardiões complacentes da ordem política e socioeconômica do capital - que alegam conhecer tudo melhor ex officio.
\end{abstract}

O rebaixamento da razão/conhecimento aos limites da manutenção da ordem do capital em crise revela o poder e a função que a educação cumpre neste projeto em relação aos pobres e explorados. Os indivíduos tomados como seres isolados/mônadas desprovidos de sua porção concreta/sóciohistórica/genérica, a qual o constitui como ser social, podem ser realinhados aos valores e conhecimentos do respeito ao sistema vigente. As personificações do capital, materializadas e representadas por este discurso político da sustentabilidade dos órgãos internacionais, devem guardar e assegurar a continuidade da desigualdade, pois sem ela não há produção de riqueza, de mercadoria, enfim, de capital. Rebaixar para submeter configura-se num dos pilares dessa proposta educadora. 
Importante observar que a necessidade do respeito, de ser democrático e pacífico não se limita apenas à submissão dos pobres/classe dominante para a manutenção do status quo. Corresponde também à manutenção de um poder político "harmônico" entre os países capitalistas. Os Estados Unidos, desde o pós-Segunda Guerra Mundial, assumiram o papel de "Estado político do capitalismo global", dado seu poder econômico, e na mesma medida, de sua força militar. Em nome de uma falsa retórica da luta pela "democracia" entre os povos, o poder político dos Estados Unidos vem há anos utilizando-se da força destrutiva de suas armas para impor a outros povos e países suas necessidades imperialistas. Conforme Mészáros (2007, p.100):

\begin{abstract}
O pluralismo no mundo do capital nada significa senão a pluralidade de capitais que não admite nenhuma consideração de igualdade. Pelo contrário, ele sempre se caracterizou pela mais pérfida ordem de hierarquias estruturais e relações de forças correspondentes, que sempre favorecem o mais forte no seu impulso para engolir o mais fraco. Assim, dada a inexorabilidade da lógica do capital, era apenas uma questão de tempo até que o dinamismo do sistema atingisse, também no nível das relações entre Estados, o estágio em que uma única potência hegemônica submetesse todas as menos poderosas, independentemente do tamanho, e afirmasse seu direito exclusivo em última análise insustentável e extremamente perigoso para o conjunto da humanidade - de ser o Estado do sistema do capital por excelência.
\end{abstract}

Por mais internacional que seja, o capitalismo (e os capitalistas com suas empresas transnacionais de hoje) não rompe com os interesses conflitantes, restritos ao enriquecimento particular de cada empresa/grupo/conglomerado individualizado. Portanto, os capitalistas se chocam entre si pela concorrência que leva ao monopólio. Os Estados nacionais não podem representar por sua própria natureza de poder político, limitado às necessidades das classes dominantes de cada país, um poder político de interesses globais, mundiais e igualitários. Sendo assim, as tensões sociais não se limitam às esferas individuais em competição na luta por sobreviver, mas também, e num volume e risco maior, resultam na "guerra" entre as diversas empresas transnacionais gigantescas em fazer crescer, expandir e manter seus lucros, com a ajuda e o apoio dos seus Estados nacionais em conflito.

Hoje, a competição entre grupos de empresas gigantescas e seus governos tem um importante elemento limitante: o enorme poder dos Estados Unidos, que tendem perigosamente a assumir o papel do 
Estado do sistema do capital em si, submetendo, por todos os meios ao seu alcance, todas as potências rivais (MÉSZÁROS, 2007, p.98).

O discurso do respeito, da paz, da justiça entre os povos não revela, em sua superfície, os conflitos e riscos crescentes entre os interesses antagônicos dos diversos capitalistas, com seus limitados poderes políticos nacionais. Desse modo, o discurso dos valores sobre o respeito silencia também o poder político dos Estados Unidos restrito aos seus interesses localizados, como se fossem os interesses da globalidade do sistema do capital. No entanto, os conflitos se aguçam mais ainda na crise do sistema, e por isso, abre-se como possibilidade histórica a fragilidade cada vez maior de os Estados Unidos manterem este domínio com a "concordância" de muitos dos países avançados ou em desenvolvimento. 


\section{REFERÊNCIAS BIBLIOGRÁFICAS}

LUKÁCS, G. II Lavoro: In: Per una Ontologia dell'essere sociale. Roma: Riuniti, 1981. (Tradução Mimeogr. de Ivo Tonet)

MÉSZÁROS, István. O desafio e o fardo do tempo histórico. São Paulo: Boitempo, 2007.

ORLANDI, Eni. Discurso e leitura. São Paulo: Cortez, 2008.

PINASSI, Maria Orlanda. Da miséria ideológica à crise do capital - uma reconciliação histórica. São Paulo: Boitempo, 2009.

TONET, Ivo. Educação, Cidadania e Emancipação Humana. ljuí: Editora Unijuí, 2005. (Coleção Fronteiras da Educação)

UNESCO. Década da Educação das Nações Unidas para o Desenvolvimento Sustentável, 2005 - 2015: documento final do esquema internacional de implementação. Brasília, 2005.

UNESCO/IBAMA. Educação para um futuro sustentável: uma visão transdisciplinar para ações compartilhadas. Brasília: Ed. IBAMA, 1999.

${ }^{\mathrm{i}}$ Prof. Adjunto da Universidade Federal de Alagoas - Campus Arapiraca - na disciplina de Pesquisa Educacional.

RECEBIDO EM: 20/11/2010

APROVADO EM: 29/11/2010 